\title{
Avanço das pesquisas envolvendo Aspergillus niger e bagaço da cana-de-açúcar como fonte de carbono visando à produção de celulases: Uma análise bibliométrica
}

\author{
Advancement of research involving Aspergillus niger \\ and sugarcane bagasse as a source of carbon for \\ the production of cellulases: A bibliometric analysis
}

Thais Caliman Catelan ${ }^{1}$, Laura Marina Pinotti ${ }^{1}$

\begin{abstract}
${ }^{1}$ Programa de Pós-graduação em Energia, Universidade Federal do Espírito Santo, Campus São Mateus, Rodovia BR 101 Norte, km 60, Bairro Litorâneo, CEP: 29932-540, São Mateus, Espirito Santo, Brasil.

e-mail: thais_cali@hotmail.com, laura.pinotti@ufes.br
\end{abstract}

\begin{abstract}
RESUMO
Uma variedade de estudos tem sido realizados com o intuito de produzir celulases de baixo custo para serem utilizadas na produção de álcool de segunda geração $(2 \mathrm{G})$ a partir de resíduos lignocelulósicos. Dentre eles destaca-se o uso de bagaço de cana-de-açúcar como fonte de carbono para o crescimento dos microrganismos. Baseado nisso, este artigo teve como objetivo realizar uma revisão bibliométrica sobre o uso do Aspergillus niger empregando como fonte de carbono o bagaço de cana-de-açúcar, pretendendo a produção de celulase, através do estudo dos avanços científicos e tecnológicos sobre os temas. Para efetuar a revisão, recorreu-se ao banco de dados Web of Science, inserindo-se quatro palavras-chave: "Aspergillus niger", "cellulase", "cane" e "submerged" entre os anos de 1945 e 2018. A partir desta pesquisa, foi possível apontar os autores, periódicos e grupos de pesquisas mais importantes neste assunto. Identificou-se um aumento do número de publicações ao longo dos anos por diversos países, revelando o interesse pela produção de celulases de menor custo para geração de álcool 2G. O Brasil foi o país com o maior número de publicações sobre o tema, devido a grande capacidade de plantio de cana-de-açúcar e produção de álcool. Pela análise das redes de co-citação dos autores verificou-se a existência de uma relação dos grupos de pesquisa no Brasil, entre as cidades de Campinas, São Paulo e Curitiba e outra associação na Dinamarca, entre as cidades de Lyngby e Copenhagen.
\end{abstract}

Palavras-chave: Bibliometria, Etanol 2G, Resíduos lignocelulósicos.

\begin{abstract}
A variety of studies have been realized with the objective of producing celulases with low cost to be used in the production of second generation alcohol $(2 \mathrm{G})$ from lignocellulosic residues. Among them, the use of sugarcane bagasse as carbon source for the growth of microorganisms is highlighted. Based on this, this article aimed to carry out a bibliometric review on the use of Aspergillus niger using sugarcane bagasse as a carbon source, aiming the production of cellulase, through the study of scientific and technological advances on the themes. To perform the review, we used the Web of Science database, inserting four keywords: "Aspergillus niger", "cellulase", "cane" and "submerged" between the years of 1945 and 2018. From this search, was possible to identify the most important authors, periodicals and research groups in this subject. It was identified an increase in the number of publications over the years by several countries, showing interest in the production of lower cost cellulases for $2 \mathrm{G}$ alcohol generation. Brazil was the country with the largest number of publications on the subject, due to the great capacity of planting sugarcane and production of alcohol. By analyzing the correlation networks of the authors it was verified the existence of a relation of the research groups in Brazil, between the cities of Campinas, São Paulo and Curitiba and another association in Denmark, between the cities of Lyngby and Copenhagen.
\end{abstract}

Keywords: Bibliometry, Ethanol 2G, Lignocellulosic Waste. 


\section{INTRODUÇÃO}

Grande parte do etanol provém de compostos amiláceos ou sacarose (melaço ou caldo de cana), dessa forma estudos de novas tecnologias estão sendo desenvolvidas para fabricação de álcool empregando biomassa não alimentícia, para que a produção industrial seja viável. Esse produto obtido a partir de biomassa lignocelulósica é conhecido como etanol de segunda geração $(2 \mathrm{G})$ e vem sendo analisado como uma alternativa renovável em substituição aos combustíveis fósseis [1].

As fontes lignocelulósicas utilizadas são principalmente resíduos agroindustriais, como bagaço de cana-de-açúcar, farelo de soja, farelo de trigo, madeira, bagaço de frutas, sabugo de milho, entre outros [2,3]. Um dos desafios existentes para o uso dessas biomassas é especialmente o emprego de enzimas comerciais, ou celulases, de altos custos para converter celulose em açúcares fermentáveis, em um processo conhecido como hidrólise enzimática [4].

No Brasil, entre os materiais lignocelulósicos que podem ser utilizados para produção de etanol e como fonte de carbono para produção de enzimas, destaca-se o bagaço de cana-de-açúcar, já que este está disponível em grandes quantidades nas usinas sucroalcooleiras [5]. Para degradar a celulose, microrganismos produzem celulases, as quais atuam em sinergismo durante o processo. O mecanismo completo de degradação envolve as ações de três principais classes de celulases: endoglucanases, exoglucanases, e $\beta$-glucosidases [6].

As celulases são produzidas por muitos microrganismos, como fungos, bactérias e actinomicetos, entretanto, os fungos apresentam maiores rendimentos para a produção dessas enzimas. Entre os fungos, os gêneros Trichoderma e Aspergillus são os mais empregados para esses processos por possuírem elevada atividade celular [7].

Entre os métodos de cultivo aplicados para produzir enzimas, os sistemas de fermentação em estado sólido (SSF) e fermentação submersa (SmF) têm sido amplamente descritos para obtenção de celulases. Entretanto, a SmF é a mais usada industrialmente, pois possui maior facilidade de monitoramento e controle dos parâmetros do processo $[8,6]$.

Resíduos agroindustriais podem ser utilizados como fonte de nutrientes, principalmente de carbono, nos processos fermentativos de diferentes tipos. O uso dessas biomassas juntamente com substâncias compostas por nitrogênio, minerais e vitaminas é eficaz para produção de elevada atividade enzimática, quando em condições satisfatórias de crescimento celular [9].

Entretanto, o uso desses resíduos lignocelulósicos como fonte de carbono pode ocasionar alguns empecilhos na medida do crescimento do microrganismo durante a fermentação, pois a quantificação das células em meios com a presença de sólidos é complexa devido à dificuldade em separar microrganismos do substrato. Sendo assim, deve-se utilizar uma metodologia de quantificação indireta da biomassa celular [6].

Dessa forma, baseado nos trabalhos estudados nos últimos anos, pretende-se realizar uma revisão bibliométrica sobre a produção de celulases utilizando como fonte de carbono o bagaço de cana-de-açúcar, a partir do fungo Aspergillus niger. A pesquisa tem como objetivo conhecer de forma geral os avanços científicos e tecnológicos realizados e identificar os principais assuntos, autores e artigos com essa temática.

\section{MATERIAIS E MÉTODOS}

Com intuito de analisar e avaliar as produções científicas relacionadas à produção de celulases a partir do fungo Aspergillus niger foi efetuada a bibliometria.

A análise bibliométrica pretende descrever, avaliar e monitorar as pesquisas publicadas, de maneira objetiva e quantitativa, sendo útil para organizar informações em um campo temático. Este método é também uma forma de análise de publicações científicas que avalia a evolução do conhecimento de um assunto, a qualidade científica e influência de obras e fontes, por meio de indicadores fornecidos por bases de dados que permitem a visualização do impacto de um determinado periódico em uma área de conhecimento $[10,11]$.

Os artigos que compõem a base de dados desta pesquisa foram obtidos da plataforma Web of Science®. Esta base de dados apresenta aproximadamente 12.000 periódicos de diferentes áreas com disponibilidade de acesso desde 1945 até o presente, além de disponibilizar ferramentas para análise de citações, referências, índice h, entre outras [12].

Definida a plataforma que seria utilizada na pesquisa, foi necessário determinar algumas palavraschave que tivessem relação com a temática desse estudo. Com isso, deu-se início a análise pela busca por trabalhos que continham a palavra "Aspergillus niger" entre os anos 1945 e 2018. Com intuito de refinar ainda mais a pesquisa e obter artigos mais alinhados ao tema, alterou-se o espaço temporal para os anos entre 
2000 e 2018 e acrescentaram-se mais três termos de pesquisa: "Cellulase", "Cane" e "Submerged".

Através da plataforma Web of Science ${ }^{\circledR}$, gerou-se um relatório de citações a partir das informações fornecidas como o valor do h-index, número total de citações, o número de citações de artigos por ano e contribuição das diferentes áreas de pesquisa. Com base nesses dados, foi possível elaborar gráficos que apresentavam a relação do número de publicações em função dos anos e dos países relacionados à pesquisa.

$\mathrm{Na}$ análise bibliométrica fez-se o uso do software CiteSpace® versão 5.0. O CiteSpace® é capaz de gerar mapas baseados em artigos científicos, permitindo mapear e visualizar novas tendências na literatura relacionados ao tema de estudo [13]. Neste software, utilizou-se a ferramenta "geographical", através da qual foram elaborados mapas no Google Earth® com a localização geográfica dos autores.

Os artigos foram organizados em ordem decrescente do número de citação. A partir dessa análise, foram selecionados os dez primeiros para realizar a leitura levando em consideração os mais relevantes ao tema. Com isso, foi possível obter uma investigação sobre as principais produções científicas que abordam a produção de celulases utilizando como fonte de carbono o bagaço de cana-de-açúcar a partir do Aspergillus niger.

Foi realizado um esquema para resumir a metodologia de estudo, apresentado na Figura 1, levando em consideração as palavras-chave, a seleção dos artigos e o mapeamento da rede de autores.

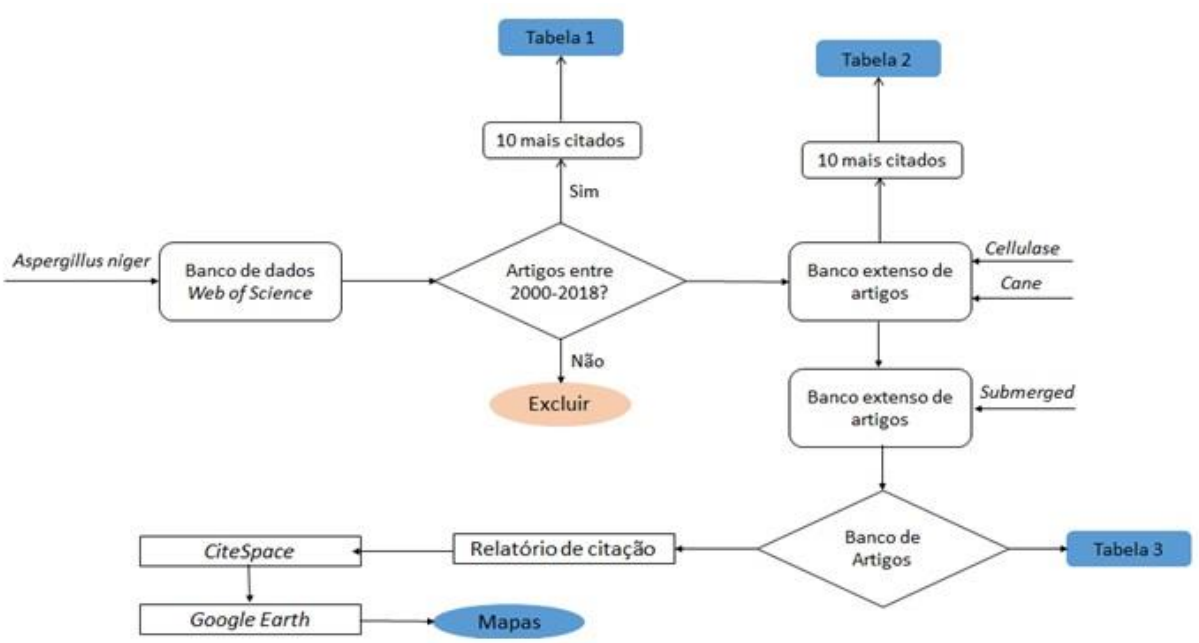

Figura 1: Fluxograma com o esquema utilizado na metodologia para análise bibliométrica.

\section{RESULTADOS E DISCUSSÃO}

A primeira análise foi realizada inserindo-se a palavra-chave "Aspergillus niger" no banco de dados do Web of Science ${ }^{\circledR}$, em que foram encontradas 19.990 publicações científicas. A partir desses dados, elaborou-se um gráfico do número de publicações que ocorreram ao longo dos anos (Figura 2).

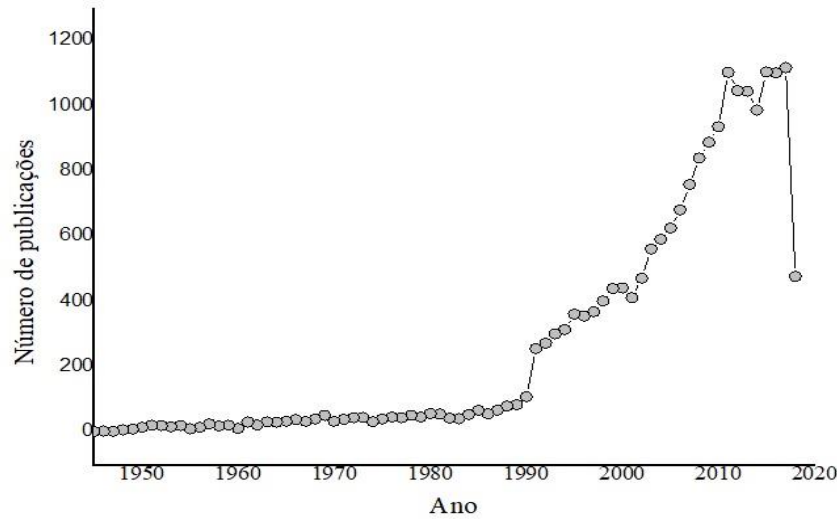

Figura 2: Número de publicações no decorrer dos anos com o tema Aspergillus niger entre 1945 e 2018. 
Baseado no gráfico observa-se que as três primeiras publicações relacionadas ao microrganismo Aspergillus niger ocorreram no ano 1945 pelos autores GEIGERHUBER e GALLI [14] no Journal HelveticaChimica Acta, STEINBERG [15] no Journal Plant Physiology e APPLING e MCCOY [16] no Technical Association Papers. O número de publicações manteve-se aproximadamente constante entre 1945 e 1989. Apesar do estudo sobre o Aspergillus ter iniciado em 1945, as pesquisas só se intensificaram no ano de 1990, quando ocorreu uma expansão significativa do número de publicações sobre o assunto.

Um dos fatores que influenciou o aumento das pesquisas neste período está relacionado com a busca de bioadsorventes originados de materiais de baixo custo para o tratamento de efluentes de indústrias, principalmente aqueles contendo resíduos de corantes, devido ao aumento das restrições ambientais ao despejo dos mesmos. Um desses tratamentos é a utilização do Aspergillus no processo de adsorção por biodegradação [17, $18,19]$. O gráfico apresenta uma redução do número de publicações no ano de 2018 , isto se deve ao fato de o ano ainda não ter chegado ao fim e poder apresentar novos artigos.

Existe um vasto número de países que vêm pesquisando sobre este microrganismo em diversas áreas de conhecimento, os 25 países de destaque pelo maior número de publicações estão apresentados na Figura 3.

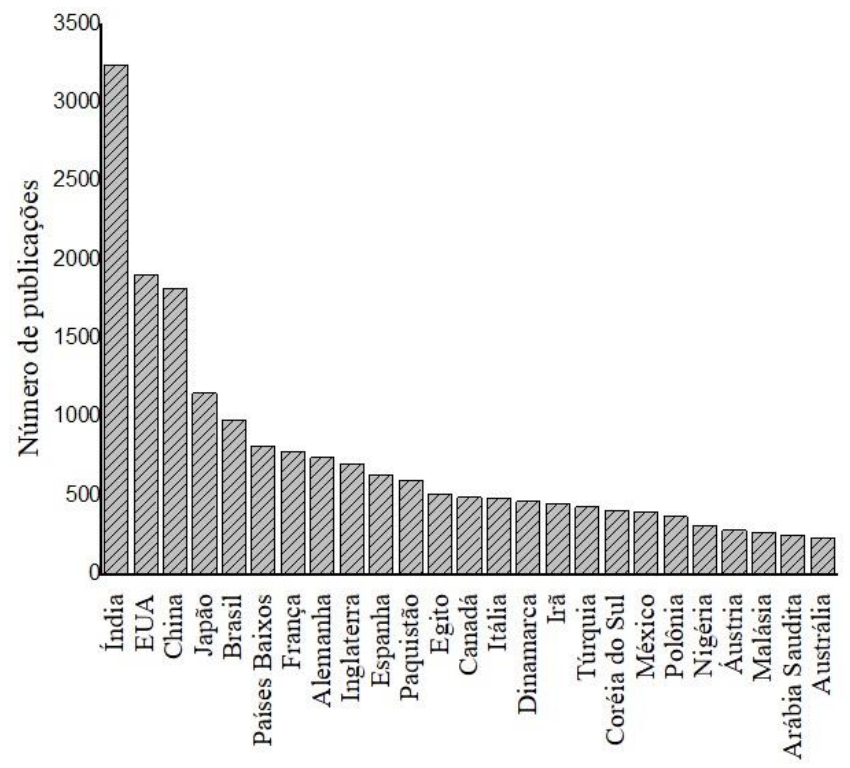

Figura 3: Número de publicações por país com o tema Aspergillus niger.

O país com maior número de publicações é a Índia, com valor de 3.246. Em segundo lugar, os Estados Unidos da América (EUA) com 1912 pesquisas e na quinta posição está o Brasil com 982 publicações.

A Índia tem apresentado um aumento no consumo de energia e na quantidade de poluentes, assim como a maior parte dos países em desenvolvimento. Este país se caracteriza por ter uma economia emergente e com rápido desenvolvimento econômico, sendo considerado o terceiro maior emissor de carbono [20]. Como consequência destes fatores, os indianos vêm investindo em pesquisas relacionadas principalmente a sustentabilidade e questões ambientais, com o objetivo de amenizar os efeitos do desenvolvimento. Tais estudos empregam o Aspergillus visando à biodegradação de poluentes.

O crescente número de pesquisas nessa área está relacionado a acordos internacionais estabelecidos, com o propósito de aumentar a preservação ambiental e atender as regulamentações constituídas por países desenvolvidos e em desenvolvimento [21]. Aliado a isso, pode-se justificar a posição dos EUA, China, Japão e Brasil no gráfico, visto que estes estão expandindo os estudos relacionados à área ambiental.

Com a finalidade de aperfeiçoar ainda mais os dados, utilizou-se a mesma palavra-chave (Aspergillusniger) e diminuiu-se o intervalo de tempo para 2000 a 2018, buscando artigos mais recentes. Foram selecionados os dez artigos mais citados para realizar uma discussão, apresentados na Tabela 1. 
Tabela 1: Publicações mais citadas com a palavra-chave Aspergillus niger na base de dados Web of Science.

\begin{tabular}{l|l}
\hline TiTULO & AUTORES \\
\hline Non-conventional low-cost adsorbents for dye removal: A review & Crini [17] \\
\hline Review of second-order models for adsorption systems & Ho [18] \\
\hline Hepcidin, a urinary antimicrobial peptide synthesized in the liver & Park et al. [22] \\
\hline Carbohydrate-binding modules: fine-tuning polysaccharide recognition & Boraston et al. [23] \\
\hline Biosorbents for heavy metals removal and their future & Wang e Chen [24] \\
\hline $\begin{array}{l}\text { Application of chitin- and chitosan-based materials for enzyme immobilizations: a } \\
\text { review }\end{array}$ & Krajewska [25] \\
\hline $\begin{array}{l}\text { Equilibrium and kinetic studies in adsorption of heavy metals using biosorbent: A } \\
\text { summary of recent studies }\end{array}$ & Febrianto et al. [26] \\
\hline $\begin{array}{l}\text { Genome sequencing and analysis of the versatile cell factory Aspergillus niger CBS } \\
513.88\end{array}$ & Pelet al. [27] \\
\hline Microbial and plant derived biomass for removal of heavy metals from wastewater & Ahluwalia e Goyal[28] \\
\hline Pectin: cell biology and prospects for functional analysis & Willats et al. [29] \\
\hline
\end{tabular}

Verificou-se que o Aspergillus foi utilizado em áreas de estudos variadas, dentre elas destacam-se as técnicas para tratamento de efluentes utilizando este microrganismo como bioadsorvente. Porém, entre os artigos mais citados não foi observada a abordagem desse microrganismo visando à produção de celulases, isto se deve ao fato dessas pesquisas estarem evoluindo recentemente. Dessa forma, cada um desses artigos foi discutido objetivando compreender o que está sendo pesquisado desde o ano 2000.

Crini [17] realizou uma revisão abordando o uso de materiais alternativos de baixo custo como adsorventes, visando à redução de poluentes de efluentes industriais a partir da técnica de adsorção. Para isto, 210 artigos foram utilizados para realizar a pesquisa bibliográfica, apresentando uma discussão sobre os materiais e métodos empregados. Dentre eles, destaca-se o uso do Aspergillus niger em processos de biossorção para remoção de corantes.

Ho [18] estudou os efeitos dos sistemas de adsorção através de modelos cinéticos de segunda ordem já existentes. Estes modelos são mais usados para adsorção de gases em um sólido, porém, nos últimos anos a equação de pseudo-segunda ordem tem sido aplicada para descrever a adsorção da remoção de poluentes do meio aquoso através dos adsorventes. Esta equação caracteriza também a biossorção por meio do Aspergillus niger.

Park et al. [22] fizeram uma relação das substâncias produzidas por insetos com função de defesa do hospedeiro, com a hepcidina, a qual foi um novo peptídeo encontrado rico em cisteína. Este composto tem origem no fígado, pode ser encontrado na urina humana e apresenta propriedades antimicrobianas. O autor apresentou a descoberta do mesmo e testou suas propriedades antissépticas. Hepcidinas apresentaram atividade antifúngica contra Candida albicans, Aspergillus fumigatus e Aspergillus niger e atividade antibacteriana contra Escherichia coli, Staphylococcus aureus, Staphylococcus epidermidis e Streptococcus do grupo B.

Boraston et al.[23] efetuaram uma revisão visando compreender a influência que a biologia estrutural teve para a evolução dos mecanismos utilizados pelos módulos de ligação a carboidratos (CBM), quando se conectam a seus ligantes alvo. Os CBMs são compostos proteicos eficazes em orientar as polissacaridases para o substrato.

Wang e Chen [24] investigaram os biossorventes usados para remoção de metais pesados através de revisões bibliográficas. Esta pesquisa concentrou-se em estudar a estrutura celular, desempenho de biossorção, pré-tratamento, modificação, regeneração/reutilização, modelagem de biossorção (modelos isotérmico e cinético), desenvolvimento de novos biossorventes e aplicação potencial dos biossorventes, dentre eles o Arpergillus niger. Destacou-se ainda uma nova tendência de usar tecnologia híbrida para remoção de poluentes, através de células vivas.

Krajewska [25] discutiu o emprego de materiais constituídos de quitina e quitosana para imobilização de enzimas, isto foi realizado a partir de uma revisão de literatura. Foram estudados 158 artigos, os quais abordaram 63 enzimas diferentes imobilizadas para inúmeros destinos, como produção de vinho, açúcar e indústria de peixe.

Febrianto et al. [26], assim como Ho [18], destacaram as principais questões da biossorção de metais pesados em relação aos equilíbrios de adsorção e modelos cinéticos.

Pel et al. [27] desenvolveram a sequência do DNA genômico de Aspergillus niger da cepa CBS 513.88. Este gene foi comparado com outros fungos do gênero Aspergillus, como A. oryzae, A. nidulans e A. fumigatus. $\mathrm{O}$ estudo destes genomas é fundamental para facilitar o desenvolvimento de novos produtos, me- 
lhorar as cepas e obter processos mais eficientes, já que o Aspergillus é caracterizado pela alta produção enzimática e grande utilização industrial (produção de alimentos, produtos farmacêuticos, fermentações).

Ahluwalia e Goyal [28] revisaram os trabalhos que empregaram o uso de biomassa microbiana e de origem vegetal, além de investigar a possibilidade de utilizá-la para remediação de metais pesados. Neste artigo, ressaltou-se a biossorção destes materiais por biomassa metabolicamente inativa, principalmente as que são subprodutos provenientes de processos fermentativos. Biomassa de Aspergillus niger, Penicillium chrysogenum, Rhizopus nigricans, Ascophyllum nodosum, Sargassum natans, Chlorella fusca, Oscillatoria anguistissima, Bacillus firmus e Streptomyces sp. possuem capacidades de adsorção de metais (especialmente $\mathrm{Pb}, \mathrm{Zn}, \mathrm{Cd}, \mathrm{Cr}$, Cu e Ni) entre 5 e $641 \mathrm{mg} . \mathrm{g}-1$.

Willats et al. [29] realizaram uma revisão com o objetivo de verificar estudos existentes a respeito da estrutura e função da pectina, a qual é um componente importante das paredes celulares primárias das plantas e apresenta polissacarídeos ricos em ácido galacturônico. O impacto da genética molecular no crescimento e desenvolvimento das plantas foi investigado em relação aos polissacarídeos pécticos.

Para obter-se um refinamento mais consistente com o tema analisado foi necessário diminuir o número de trabalhos encontrados, já que este foi muito extenso. Acrescentou-se o termo "cellulase" na pesquisa entre os anos 2000 e 2018. Dessa forma, encontrou-se 973 arquivos mais alinhados com o tema. A Índia, China e Brasil lideraram a quantidade de trabalhos publicados com 170, 154, 112 artigos, respectivamente.

Porém, a pesquisa ainda apresentou uma grande quantidade de artigos, sendo necessária a inserção de mais uma palavra-chave para que fosse possível alcançar um número de publicações reduzido e que viabilizasse as análises. O termo de pesquisa adicionado foi "cane" (entre 2000 e 2018) e obteve-se como resultado 42 artigos publicados. A Figura 4 apresenta o número de publicações ao longo dos anos com as três palavraschave.

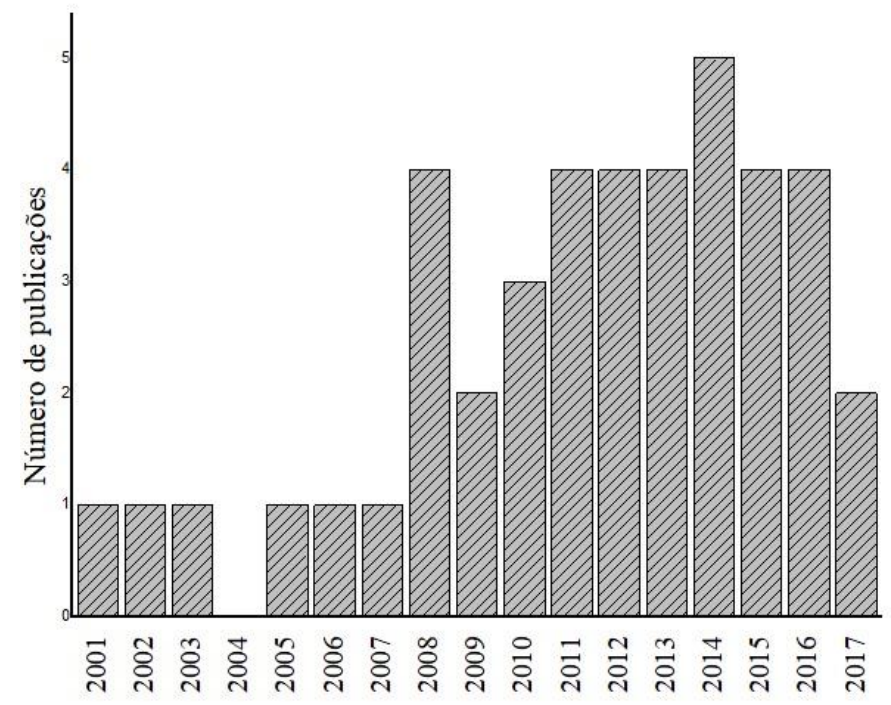

Figura 4: Número de publicações no decorrer dos anos com as palavras-chave Aspergillus niger, cellulase e cane entre 2000 e 2018.

Observa-se que o gráfico da Figura 4 não apresenta um comportamento padrão do avanço das pesquisas. Nos anos de 2001 a 2007 ocorreu um desempenho constante, com exceção de 2004 que não teve nenhuma publicação. Em 2008, as pesquisas se intensificam e manteve uma média de quatro publicações até o ano de 2016. Porém, em 2017 os dados fornecem uma queda no número de artigos.

No ano de 2008 ocorreu um aumento significativo dos estudos, visto que, neste período, o preço do barril do petróleo atingiu um recorde de US\$ 140/barril (junho de 2008). Como consequência disto, sucedeuse a busca mundial por combustíveis alternativos em substituição ao petróleo. No Brasil, além da minimização de custos, priorizaram-se também os fatores ambientais e a produção de etanol em grande escala visando à exportação [30].

Muitos países têm pesquisado sobre o uso de bagaço de cana-de-açúcar como fonte de carbono para 
produção de celulases, sendo que os que mais publicaram são apresentados no gráfico da Figura 5.

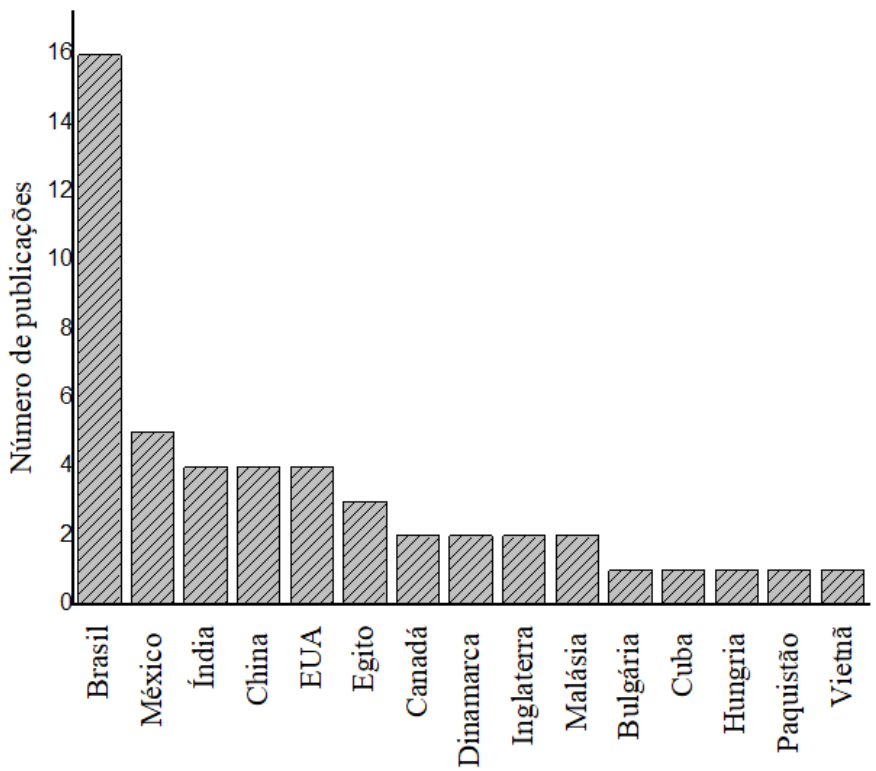

Figura 5: Número de publicações por país com as palavras-chave Aspergillus niger, cellulase e cane entre 2000 e 2018.

Analisou-se pelo gráfico da Figura 5 que o Brasil é o país que se destaca nas pesquisas sobre uso do Aspergillus niger para produção de celulases tendo como fonte de carbono o bagaço da cana-de-açúcar, com 16 publicações entre 2000 e 2018, seguido pelo México (cinco artigos) e Índia (quatro artigos).

Devido às crises relacionadas com a escassez de combustíveis fósseis e problemas ambientais causados nestes últimos anos, muitas alternativas têm sido desenvolvidas para resolver essas questões, dentre elas os biocombustíveis têm recebido grande atenção no cenário global. Diversos resíduos agroindustriais como bagaços, grãos, cascas, palhas e outros são utilizados para a produção de etanol. Entre eles, o bagaço de canade-açúcar apresentou maiores vantagens devido à grande disponibilidade em países como Brasil, México, Índia e China [31].

O Brasil se evidencia nas pesquisas por gerar um grande número de resíduos florestais e agroindustriais. Dessa forma, a crescente busca por pesquisas para dar um destino viável e lucrativo para os resíduos sólidos tem aumentado significativamente. Uma alternativa é a bioconversão do bagaço de cana para produção de álcool 2G, o qual é o etanol gerado a partir de matéria lignocelulósica [32].

Das 42 publicações, selecionaram-se os 10 artigos mais citados no período entre 2000 e 2018 . Estes são apresentados na Tabela 2.

Tabela 2: Publicações mais citadas com as palavras-chave Aspergillus niger, cellulase e cane na base de dados Web of Science (2000-2018).

\begin{tabular}{l|l}
\hline TíTULO & AUTORES \\
\hline $\begin{array}{l}\text { Cellulase production using biomass feed stock and its application in lignocellulose sac- } \\
\text { charification for bio-ethanol production }\end{array}$ & Sukumaran et al. [1] \\
\hline $\begin{array}{l}\text { Enhanced enzyme production from mixed cultures of Trichoderma reesei RUT-C30 } \\
\text { and Aspergillus niger LMA grown as fed batch in a stirred tank bioreactor }\end{array}$ & Ahamed e Vermette [33] \\
\hline $\begin{array}{l}\text { Value-addition of agricultural wastes for augmented cellulase and xylanase production } \\
\text { through solid-state tray fermentation employing mixed-culture of fungi }\end{array}$ & Dhillonet al. [7] \\
\hline $\begin{array}{l}\text { Effect of substrate particle size and additional nitrogen source on production of lignocellu- } \\
\text { lolytic enzymes by Pleurotus ostreatus strains }\end{array}$ & Membrilloet al. [34] \\
\hline $\begin{array}{l}\text { Effect of initial moisture content on two Amazon rainforest Aspergillus strains cultivated } \\
\text { on agro-industrial residues: Biomass-degrading enzymes production and characterization }\end{array}$ & Delabonaet al. [2] \\
\hline Modeling the effects of solid state fermentation operating conditions on endoglucanase & Farinas et al. [35] \\
\hline
\end{tabular}




\begin{tabular}{l|l}
\hline production using an instrumented bioreactor & \\
\hline $\begin{array}{l}\text { Purification and Properties of Endoglucanase from a Sugar Cane Bagasse Hydrolyzing } \\
\text { Strain,Aspergillus glaucusXC9 }\end{array}$ & Tao et al. [36] \\
\hline $\begin{array}{l}\text { Optimization of compatible mixed cultures for liquid state bioconversion of municipal } \\
\text { wastewater sludge }\end{array}$ & Alam et al. [37] \\
\hline $\begin{array}{l}\text { Production of cellulolytic enzymes from ascomycetes: Comparison of solid state and sub- } \\
\text { merged fermentation }\end{array}$ & Hansen et al. [4] \\
\hline $\begin{array}{l}\text { Co-cultivation of Trichodermareese } i \text { RutC30 with three black Aspergillus strains facilitates } \\
\text { efficient hydrolysis of pretreated wheat straw and shows promises for on-site enzyme pro- } \\
\text { duction }\end{array}$ & Kolasa et al. [38] \\
\hline
\end{tabular}

Na Tabela 2 considerou-se que os artigos foram nivelados e se encontram mais alinhados ao tema. Sukumaran et al. [1] produziram celulases para sacarificação (empregando como biomassas o bagaço de cana, a palha de arroz e a aguapé) através do processo de fermentação em estado sólido (FES) em farelo de trigo. Para produção de celulases foram utilizados dois fungos: Trichoderma reesei e Aspergillus niger. Concluiuse que as preparações enzimáticas produzidas FES por fungos podem ser empregadas para a hidrólise de biomassa.

Ahamed e Vermette [33] investigaram o aumento do rendimento da produção de celulases a partir de culturas mistas de Trichoderma reesei e Aspergillus niger em biorreator, para converter substrato de celulose em açúcares solúveis. Os resultados dos experimentos de cultura mista exibiram um aumento significativo na produção enzimática em comparação com monoculturas de Aspergillus niger.

Dhillon et al. [7] avaliaram a capacidade dos resíduos agrícolas (palha de arroz, couve-flor, polpa de tangerina "Kinnow", ervilhas e farelo de trigo) para produzir celulase e hemicelulase mediante culturas individuais e mistas de Aspergillus niger e Trichoderma reseei. Os autores concluíram que uma maior atividade de celulase pode ser alcançada através de fermentação em estado sólido de cultura mista em bandejas, porém devem ser avaliadas as condições ótimas do processo. É aconselhável que a utilização de resíduos atenda alguns critérios para o processo ser viável, como: utilizar resíduos que causariam problemas ambientais, produzir celulases a baixo custo e possuir uma técnica simples que não requer instrumentos sofisticados com aplicações práticas.

Membrillo et al.[34] estudaram a produção enzimática a partir de duas linhagens de Pleurotus ostreatus (IE-8 e CP-50) cultivadas em diferentes tamanhos de partícula de extrato de palha de trigo. As células produzidas na cultura foram inoculadas na fermentação em estado sólido usando bagaço de cana. Nesse contexto, verificou-se que a cepa IE-8 produziu os níveis mais elevados de enzimas em relação a CP-50.

Delabona et al. [2] examinaram o efeito do teor de umidade inicial do farelo de trigo na fermentação em estado sólido (FES) com a cultura de Aspergillus niger P47C3 e Aspergillus fumigatus P40M2. A produção enzimática foi avaliada empregando como fonte de carbono o farelo de trigo, bagaço de cana, farelo de soja e bagaço de laranja. As fontes de carbono mais eficazes para a produção do complexo enzimático foram as de farelo de trigo e de soja.

Farinas et al.[35] basearam-se no fato de que a fermentação em estado sólido (FES) possui difícil controle das variáveis do processo, as quais influenciam o crescimento microbiano e a produção de metabólitos. Dessa forma, as condições operacionais foram avaliadas para produzir endoglucanases por meio de $A s$ pergillus niger. Aplicou-se a FES com farelo de trigo em um biorreator equipado com um sistema de monitoramento e controle automatizado online. O sistema de controle empregado foi eficiente para estimar as variáveis que atuavam na produção de enzimas em FES.

Tao et al. [36] pesquisaram as propriedades das endoglucanases originadas do cultivo de Aspergillus glaucus XC9 por meio do bagaço de cana como fonte de carbono. A maior produção da enzima foi no quarto dia a $30{ }^{\circ} \mathrm{C}$. As endoglucanases foram testadas na hidrólise da carboximetilcelulose sódica (CMC-Na) em diferentes condições de $\mathrm{pH}$ e temperatura, sendo que os melhores resultados foram em $\mathrm{pH} 4,0$ e $50{ }^{\circ} \mathrm{C}$. $\mathrm{O}$ efeito dos íons metálicos também foi avaliado na hidrólise e concluiu-se que a atividade enzimática foi estimulada por $\mathrm{Fe}^{2+}$ e $\mathrm{Mn}^{2+}$, mas inibida por $\mathrm{Cd}^{2+}, \mathrm{Pb}^{2+}$ e $\mathrm{Cu}^{2+}$.

Alam et al. [37] investigaram a formação de culturas mistas para tratamento de lodo de águas residuárias em um processo de bioconversão. As linhagens de fungos estudadas foram: Penicillium corylophilum (P), Aspergillus niger (A), Trichoderma harzianum (T) e Phanerochaete chrysosporium (PC). Realizaram-se as seguintes combinações (P/A), (P/PC), (P/T), (A/T), (A/PC) e (T/PC). A partir das análises concluiu-se que as combinações de P/A, P/PC e A /PC mostraram crescimento compatível e as combinações P/T, A/T e T/PC eram culturas incompatíveis. 
Hansen et al. [4] revisaram os trabalhos que abordavam os perfis enzimáticos para vários ascomicetos, abrangendo gêneros e espécies filogeneticamente distintos. Além disso, avaliou-se a escolha de meios, métodos de cultivo e ensaios que afetavam a atividade enzimática. Existem dois principais processos para produção de enzimas degradadoras de celulose, a fermentação submersa (FS) e fermentação em estado sólido (FES). A FS é o método mais comum para a produção de enzimas comerciais, porém a FES é uma forma promissora de produzir títulos de enzimas mais altos em comparação com FS. Assim sendo, os autores forneceram comparações entre a produção de celulases em FES com FS para contribuir para pesquisas futuras.

Kolasaet al. [38] realizaram o co-cultivo de Trichoderma reesei RUTC30 com Aspergillus saccharolyticus AP, Aspergillus carbonarius ITEM 5010 e Aspergillus niger CBS 554.65 em fermentação em estado sólido para identificar a atividade enzimática e a hidrólise de palha de trigo. Os autores concluíram que o co-cultivo de Trichoderma reesei com Aspergillus saccharolyticus ou Aspergillus carbonarius pode ser uma alternativa competitiva com monoculturas de enzimas ou com enzimas comerciais.

Ao realizar a análise da Tabela 2, percebeu-se que as publicações encontradas ainda não estavam refinadas o suficiente, pois havia muitas pesquisas com métodos que não eram de interesse. Com a finalidade de obter resultados relevantes para o presente artigo, adicionou-se mais uma palavra-chave (Submerged) com a intenção de encontrar trabalhos que discutiam e analisavam a produção de celulases em fermentação submersa. Com as quatro palavras-chave (Aspergillus niger, cellulase, cane e submerged) encontrou-se 11 trabalhos, apresentados na Tabela 3.

Tabela 3: Publicações mais citadas com as palavras-chave Aspergillus niger, cellulase, cane e submerged na base de dados Web of Science (2000-2018).

\begin{tabular}{l|l}
\hline TíTULO & AUTORES \\
\hline $\begin{array}{l}\text { Production of cellulolytic enzymes from ascomycetes: Comparison of solid state and sub- } \\
\text { merged fermentation }\end{array}$ & Hansen et al. [4] \\
\hline $\begin{array}{l}\text { Production efficiency versus thermostability of (hemi)cellulolytic enzymatic cocktails from } \\
\text { different cultivation systems }\end{array}$ & Vasconcellos et al. [5] \\
\hline $\begin{array}{l}\text { Effect of media composition and growth conditions on production of beta-glucosidase } \\
\text { by Aspergillus niger C-6 }\end{array}$ & Garcia-Kirchner et al. [39] \\
\hline $\begin{array}{l}\text { Soybean protein as a cost-effective lignin-blocking additive for the saccharification of sugar- } \\
\text { cane bagasse }\end{array}$ & Florencio et al. [8] \\
\hline $\begin{array}{l}\text { Indirect method for quantification of cellular biomass in a solidscontaining medium used as } \\
\text { pre-culture for cellulase production }\end{array}$ & Cunha et al. [6] \\
\hline $\begin{array}{l}\text { On-Site Production of Enzymatic Cocktails Using a Non-conventional Fermentation Method } \\
\text { with Agro-Industrial Residues as Renewable Feedstocks }\end{array}$ & Cunha et al. [40] \\
\hline $\begin{array}{l}\text { Agro-residues as Alternative for Xylanase Production by Filamentous Fungi } \\
\text { Xylanase production by endophytic Aspergillus niger using pentose-rich hydrothermal liquor } \\
\text { from sugarcane bagasse }\end{array}$ & Knob et al. [41] et al. [42] \\
\hline $\begin{array}{l}\text { Isolation and Characterization of a Xylan-Degrading Enzyme from Aspergillus niger van } \\
\text { Tieghem LPM 93 with Potential for Industrial Applications }\end{array}$ & Milanezi et al. [43] \\
\hline $\begin{array}{l}\text { Cost-effective production of biotechnologically important hydrolytic enzymes by Spo- } \\
\text { rotrichum thermophile }\end{array}$ & Bala e Singh [44] \\
\hline $\begin{array}{l}\text { Mycelial growth interactions and mannan-degrading enzyme activities from fungal mixed } \\
\text { cultures grown on palm kernel cake }\end{array}$ & Iluyemi e Hanafi [45] \\
\hline
\end{tabular}

O trabalho de Hansen et al. [4] já foi discutido na Tabela 2. Dando continuidade as análises, Vasconcellos et al. [5] procuraram investigar os diferentes sistemas de cultivo tendo como medida de resposta a eficácia da produção e termoestabilidade das enzimas celulolíticas. O Aspergillus niger foi cultivado usando como fonte de carbono o bagaço de cana nas técnicas de fermentação submersa (FS), fermentação em estado sólido (FES) e fermentação sequencial (junção da FS e FES). Por fim, os resultados mostraram que o potencial da FES para a produção de enzimas celulolíticas com maior estabilidade é mais viável.

Garcia-Kirchner et al. [39] pesquisaram o cultivo de Aspergillus niger para produção de $\beta$-glucosidase, com diferentes condições reacionais da fermentação submersa, tais como: temperatura de crescimento, composição do meio, pH, agitação e aeração, empregando meio de cultura com calda de xarope de milho e bagaço de cana-de-açúcar como fonte de carbono. A máxima produção de enzima foi de 7,2 UI/mL obtido em 3 dias de fermentação. O microrganismo utilizado foi considerado com potencial para atingir uma alta produ- 
ção enzimática.

Florencio et al.[8] exploraram a proteína de soja como um aditivo alternativo na hidrólise enzimática do bagaço da cana-de-açúcar. Neste processo, utilizou-se coquetéis enzimáticos de Aspergillus niger e Trichoderma reesei cultivados em fermentação sólida, submersa e sequencial. A proteína de soja conseguiu aumentar a hidrólise do bagaço em 2 vezes para os coquetéis enzimáticos em FES, sendo considerada um aditivo eficaz e barato para converter a biomassa.

Cunha et al. [6] testaram uma metodologia capaz de quantificar indiretamente a biomassa durante o processo de fermentação, já que a biomassa sólida é difícil de ser medida. O cultivo de Aspergillus niger com bagaço de cana foi realizado por meio de uma fermentação combinada, com tempo de $24 \mathrm{~h}$ seguida pela adição de um meio líquido e cultura em FS por 48 h. Este método permitiu uma atividade de endoglucanase superior ao da FS convencional. Logo, o procedimento é uma opção promissora para ser empregado em escala industrial.

Cunha et al. [40] avaliaram a produção de enzimas com subprodutos agroindustriais (farelo de trigo, farelo de soja e bagaço de cana-de-açúcar) em um método não convencional de fermentação em estado sólido e submerso. Os autores estimaram as atividades enzimáticas e o desempenho na sacarificação do bagaço de cana através de coquetéis enzimáticos produzidos com diferentes resíduos agroindustriais.

Knob et al.[41] revisaram alternativas para a produção de xilanase a partir de resíduos agrícolas como substratos. Os resíduos agroindustriais, como farelo de trigo, palha de trigo e bagaço de cana, têm sido investigados por apresentarem grandes rendimentos de xilanase e baixos custos de produção. Entretanto, muitos resíduos (como palha de sorgo e subprodutos do café) ainda não foram testados, sendo considerados com grande potencial para produção de xilanase, merecendo destaque para pesquisas futuras.

Robl et al. [42] discutiram a produção de xilanase e outras enzimas acessórias por meio do cultivo de Aspergillus niger DR02 utilizando o bagaço de cana-de-açúcar como fonte de carbono. O diferencial deste artigo é o desenvolvimento de cultivos submersos em batelada e batelada alimentada, com a finalidade de minimizar a toxicidade do meio e aumentar a produção de enzimas. Concluiu-se que o cultivo em batelada alimentada com limite de carbono reduz a repressão catabólica de fungos e minimiza os efeitos negativos de compostos tóxicos presentes.

Milanezi et al. [43] relataram a produção, purificação e caracterização de uma enzima de degradação de xilana da linhagem de Aspergillus niger van Tieghem LPM 93 cultivada em meio líquido submerso contendo bagaço de cana-de-açúcar como fonte de carbono. $\mathrm{O}$ fungo apresentou altos níveis de atividade xilanolítica após o segundo dia de cultivo, e esta permaneceu constante até o $50^{\circ}$ dia.

Bala e Singh [44] estudaram a produção de xilanase e três celulases, endo- $\beta$-1,4-glucanase (CMCase), exo- $\beta$-1,4-glucanase (FPase) e $\beta$-glicosidase (BGL) em fermentação submersa usando como meio o melaço de cana. Este processo obteve como resultado 72,410, 36,420, 32,420 e 5180 U/L de xilanase, CMCase, FPase e $\beta$-glicosidase, respectivamente. Portanto, a produção simultânea de enzimas celulolíticas e xilanolíticas foi eficiente para a sacarificação de produtos lignocelulósicos na geração de açúcares monoméricos e oligoméricos.

Iluyemi e Hanafi [45] examinaram a produção de enzimas capazes de degradar manana contida em torta de dendê. Realizaram-se interações fúngicas com Sclerotium rolfsii e Aspergillus nigerco-cultivadas a partir de três linhagens de Trichoderma (Trichoderma harzianum, Trichoderma longiobrachiatum e Trichoderma koningii). As monoculturas e co-culturas desses fungos foram cultivados em meio submerso por 13 dias com torta de dendê como fonte de carbono. A co-cultura de Aspergillus niger com as estirpes de Trichoderma mostrou um aumento das atividades enzimáticas de degradação de manana em relação às outras culturas.

Com o objetivo de conhecer a relação entre os autores dos artigos da Tabela 3, utilizou-se a ferramenta Geographical do software Citespace ${ }^{\circledR}$, gerando mapas com a localização geográfica dos autores através do Google Earth®. Essas ilustrações estão apresentadas na Figura 6. 


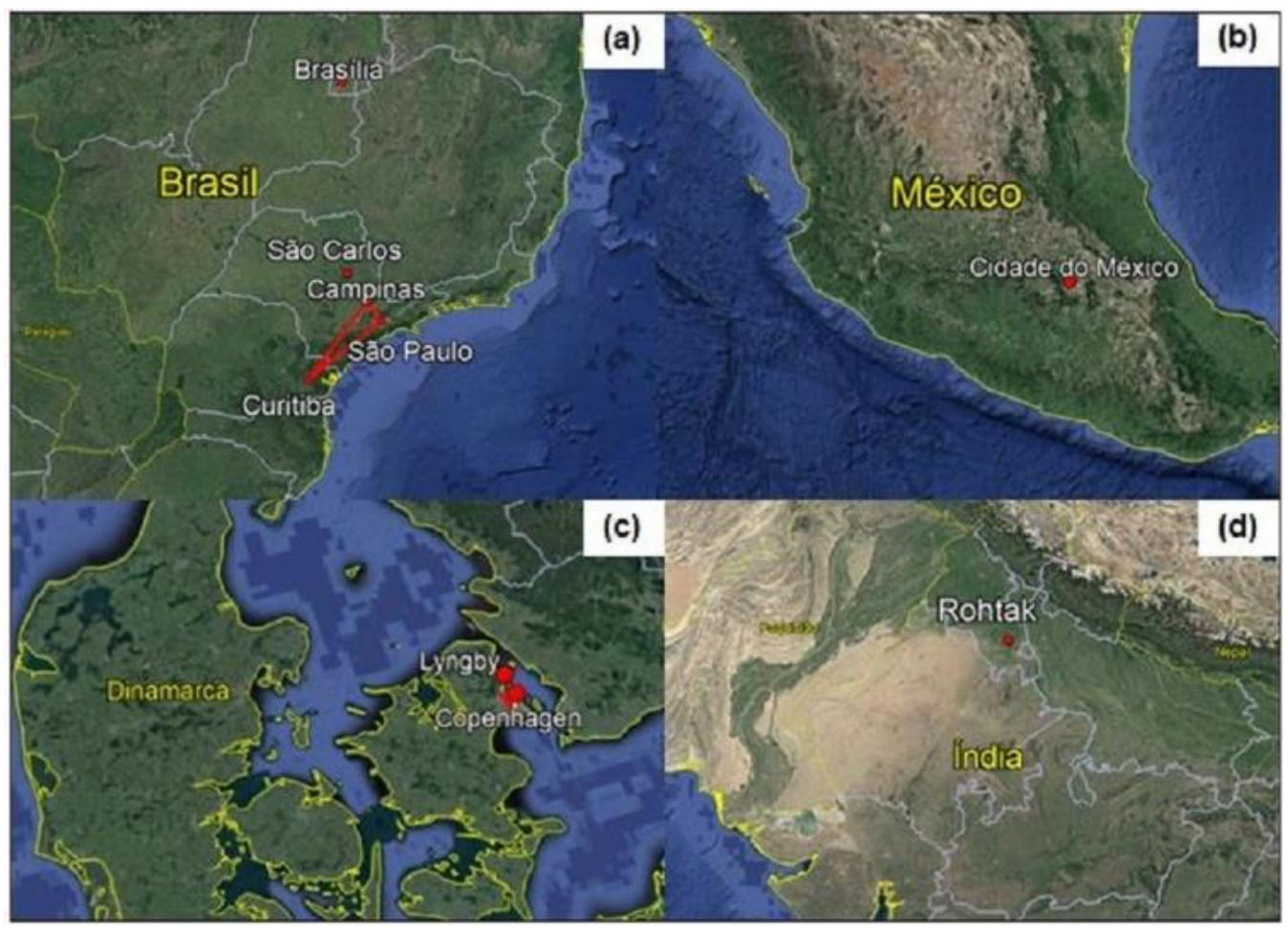

Figura 6: Mapa de localização dos autores de artigos com as palavras-chave Aspergillus niger, Cellulase, Cane e Submerged os anos 2000 e 2018.

A Figura 6(a) mostra os grupos de pesquisas existentes no Brasil, dentre eles destaca-se a relação entre os centros de pesquisa localizados em Campinas, São Paulo e Curitiba. Porém as equipes de Brasília e São Carlos não apresentam relação entre si e nem com outros grupos nacionais ou internacionais.

A parte (b) e (d) da Figura apresentam comunidades isoladas de estudo, não tendo relação com outros centros de exploração científica. A Figura 6(c) exibe a interconexão existente entre os grupos das cidades de Lyngby e Copenhagen na Dinamarca.

\section{CONCLUSÕES}

Baseado na análise bibliométrica realizada, foi possível investigar os principais assuntos, autores e artigos que tiveram alguma relação com o estudo do Aspergillus niger e que utilizaram o bagaço da cana de açúcar como fonte de carbono. Portanto, observou-se a relevância do assunto de estudo em diversos países e áreas de pesquisa.

Nos primeiros estudos analisados, verificou-se que o Aspergillus niger foi empregado principalmente em tratamentos de bioadsorção, visando remover metais e corantes de efluentes industriais. Com o passar dos anos, as pesquisas avançaram e a busca por combustíveis não fósseis aumentaram, assim, este microrganismo se tornou objeto de estudo para produção de celulases pretendendo baratear a geração do álcool $2 \mathrm{G}$, revelando-se com grande potencial para este processo.

Foi possível examinar o progresso das técnicas utilizadas para produção de celulases por meio de diferentes metodologias testadas, relacionadas a microrganismos, métodos de fermentação (submersa ou em estado sólido), meios de fermentação e ensaios experimentais (quantidade de oxigênio dissolvido, pH, temperatura, concentração, entre outros).

Dessa forma, a pesquisa bibliométrica é essencial para conhecer os avanços das condições que favorecem o crescimento dos microrganismos, e, consequentemente, a produção de celulases. Aliado a isso, a maioria dos autores propuseram a utilização do bagaço de cana e outros resíduos agroindustriais como forma de amenizar a poluição e gerar um produto viável de menor custo.

\section{AGRADECIMENTOS}

Os autores agradecem à Coordenação de Aperfeiçoamento de Pessoal de Nível Superior (CAPES) pelo apoio financeiro. 


\section{BIBLIOGRAFIA}

[1] SUKUMARAN, R. K., SINGHANIA, R. R., MATHEW, G. M., et al., "Cellulase production using biomass feed stock and its application in lignocellulose saccharification for bio-ethanol production", Renewable Energy, v.34, n. 2, pp. 421-424, Feb. 2009.

[2] DELABONA, P. S., PIROTA, R. D. P. B., CODIMA, C. A., et al., "Effect of initial moisture content on two Amazon rainforest Aspergillus strains cultivated on agro-industrial residues: Biomass-degrading enzymes production and characterization”, Industrial Crops and Products, v. 42, pp. 236-242, Mar. 2013.

[3] JAMPALA, P., TADIKAMALLA, S. M., PREETHI, M., et al., "Concurrent production of cellulase and xylanase from Trichodermareesei NCIM 1186: enhancement of production by desirability-based multiobjective method", 3 Biotech, v. 7, n. 14, pp. 1-13, May. 2017.

[4] HANSEN, G. H., LUBECK, M., FRISVAD, J. C., et al., "Production of cellulolytic enzymes from ascomycetes: Comparison of solid state and submerged fermentation”, Process Biochemistry, v. 50, n. 9, pp. 1327-1341, Sept. 2015.

[5] VASCONCELlOS, V. M., TARDIOLI, P. W., GIORDANO, R. L. C., et al., "Production efficiency versus thermostability of (hemi)cellulolytic enzymatic cocktails from different cultivation systems", Process Biochemistry, v. 50, n.11, pp. 1701-1709, Nov. 2015.

[6] CUNHA, F. M., BACCHIN, A. L. G., HORTA, A. C. L., et al., "Indirect Method for Quantification of Cellular Biomass in a Solids containing Medium Used as Pre-culture for Cellulase Production", Biotechnology and Bioprocess Engineering, v.17, pp. 100-108, Feb. 2012.

[7] DHILLON, G. S., OBEROI, H. S., KAUR, S., et al., "Value-addition of agricultural wastes for augmented cellulase and xylanase production through solid-state tray fermentation employing mixed-culture of fungi", Industrial Crops and Products, v.34, pp. 1160-1167, July 2011.

[8] FLORENCIO, C., BADINO, A. C., FARINAS, C.S., "Soybean protein as a cost-effective lignin-blocking additive for the saccharification of sugarcane bagasse", Bioresource Technology, v. 221, pp. 172-180, Dec. 2016.

[9] AGUIAR, L. C., MENEZES, T. J. B.,"Produção de celulases e xilanase por Aspergillusniger iz-9 usando fermentação submersa sobre bagaço de cana-de-açúcar”,Boletim Centro de Pesquisa de Processamento de Alimentos, v. 18, n. 1, pp. 57-70, June2000.

[10] DZIKOWSKI, P., “A bibliometric analysis of born global firms”, Journal of Business Research, v. 85, pp. 281-294, Apr. 2018.

[11] ALBORT-MORANT, G., RIBEIRO-SORIANO, D., “A bibliometric analysis of international impact of business incubators”, Journal of Business Research, v. 69, n. 5, pp. 1775-1779, May 2016.

[12] CAPES,http://www.periodicos.capes.gov.br, Acessado em junho de 2018.

[13] CHEN, C., "CiteSpace II: Detecting and visualizing emerging trends and transient patterns in scientific literature", Journal of the American Society for Information Science and Technology, v. 57, n. 3, pp. 359-377, Feb. 2006.

[14]GEIGERHUBER, M., GALLI, H.,"Uber den nachweis der 1-ascorbinsaurealsstoffwechselprodukt von Aspergillus niger”, Helvetica ChimicaActa, v. 28, n. 1, pp. 248-250, 1945.

[15] STEINBERG, R. A., “A dibasal (minimum salt, maximum yield) solution for Aspergillus niger - acidity and magnesium optimum”,Plant Physiology, v. 20, n. 4, pp. 600-608, Oct. 1945.

[16] APPLING, J. W., MCCOY, J. F., "Relative toxicity of disinfectants recommended for use in the paper industry .2. Inhibiting concentrations for bacillus-mycoides and aspergillus niger", Technical Association Papers, v. 28, pp. 132-135, June 1945.

[17] CRINI, G., "Non-conventional low-cost adsorbents for dye removal: A review", Bioresource Technology, v. 97, n. 9, pp.1061-1085, June 2006.

[18] HO, Y., "Review of second-order models for adsorption systems", Journal of Hazardous Materials, v. 136, n. 3, pp. 681-689, Aug. 2006.

[19] FU, Y. Z., VIRARAGHAVEN, T., "Removal of a dye from an aqueous solution by the fungus Aspergillus niger”, Water Quality Research Journal of Canada, v. 35, n. 1, pp. 95-111, Nov. 2000.

[20] AHMAD, A., ZHAO, Y., SHAHBAZ, M., et al., "Carbon emissions, energy consumption and economic growth: An aggregate and disaggregate analysis of the Indian economy", Energy Policy, v. 96, pp. 131-143, 2016. 
[21] MOREIRA, H. M., GIOMETTI, A. B. R.,"Protocolo de Quioto e as possibilidades de inserção do Brasil no Mecanismo de Desenvolvimento Limpo por meio de projetos em energia limpa",Contexto Internacional, v. 30, n. 1, pp. 9-47, Apr. 2008.

[22] PARK, C. H., VALORE, E. V., WARING, A. J., et al., "Hepcidin, a urinary antimicrobial peptide synthesized in the liver", Journal of Biological Chemistry, v. 276, n. 11, pp. 7806-7810, Mar. 2001.

[23] BORASTON, A. B., BOLAM, D. N., GILBERT, H. J., et al., "Carbohydrate-binding modules: finetuning polysaccharide recognition”, Biochemical Journal, v. 382, n. 3, pp. 769-781, Sept. 2004.

[24] WANG, J., CHEN, C., "Biosorbents for heavy metals removal and their future", Biotechnology Advances, v. 27, n. 2, pp. 195-226, Mar. 2009.

[25] KRAJEWSKA, B., "Application of chitin- and chitosan-based materials for enzyme immobilizations: a review”, Enzyme and Microbial Technology, v. 35, pp. 126-139, Aug. 2004.

[26] FEBRIANTO, J., KOSASIH, A. N., SUNARSO, J., et al., "Equilibrium and kinetic studies in adsorption of heavy metals using biosorbent: A summary of recent studies", Journal of Hazardous Materials, v. 162, n. 2-3, pp. 616-645, Mar. 2009.

[27] PEL, H. J., WINDE, J. H., ARCHER, D.B.,et al.,"Genome sequencing and analysis of the versatile cell factory Aspergillusniger CBS 513.88”, Nature Biotechnology, v. 25, n. 2, pp. 221-231, Jan. 2007.

[28] AHLUWALIA, S. S., GOYAL, D., "Microbial and plant derived biomass for removal of heavy metals from wastewater", Bioresource Technology, v. 98, n. 12, pp. 2243-2257, Sept. 2007.

[29] WILlATS, W. G. T., MCCARTNEY, L., MACKIE, W., et al., "Pectin: cell biology and prospects for functional analysis”, Plant Molecular Biology, v. 47, pp. 9-27, Sept. 2001.

[30] KOHLHEPP, G.,"Análise da situação da produção de etanol e biodiesel no Brasil”,Estudos Avançados, v.24, n. 68, pp. 223-253, Aug. 2010.

[31] ANTUNES, F. A. F., CHANDELL, A.K., BRUMANO, L. P., et al., "A novel process intensification strategy for second-generation ethanol production from sugarcane bagasse in fluidized bed reactor", Renewable Energy, v. 124, pp. 189-196, Aug. 2018.

[32] FLORENCIO, C., BADINO, A. C., FARINAS, C. S., “Desafios relacionados à produção e aplicação das enzimas celulolíticas na hidrólise da biomassa lignocelulósica", Química Nova, v. 40, n. 9, pp. 10821093,Sept. 2017.

[33] AHAMED, A., VERMETTE, P., "Enhanced enzyme production from mixed cultures of Trichodermareesei RUT-C30 and Aspergillusniger LMA grown as fed batch in a stirred tank bioreactor", Biochemical Engineering Journal, v. 42, n. 1, pp. 41-46, Oct. 2008.

[34] MEMBRILLO, I., SANCHEZ, C., MENESES, M., et al., "Effect of substrate particle size and additional nitrogen source on production of lignocellulolytic enzymes by Pleurotusostreatus strains", Bioresource Technology, v. 99, n. 16, pp. 7842-7847, Nov. 2008.

[35] FARINAS, C. S., VITCOSQUE, G. L., FONSECA, R. F., et al., "Modeling the effects of solid state fermentation operating conditions on endoglucanase production using an instrumented bioreactor", Industrial Crops and Products, v. 34, n. 1, pp. 1186-1192, July 2011.

[36] TAO, Y., ZHU, X., HUANG, J., et al., "Purification and Properties of Endoglucanase from a Sugar Cane Bagasse Hydrolyzing Strain, Aspergillusglaucus XC9”, Journal of Agricultural and Food Chemistry, v. 58, n.10, pp. 6126-6130, May 2010.

[37] ALAM, M. Z., FAKHRU'L-RAI, A., ABD-AZIZ, S., et al., "Optimization of compatible mixed cultures for liquid state bioconversion of municipal wastewater sludge”, Water Air and Soil Pollution, v. 149, pp. 113126, Oct. 2003.

[38] KOLASA, M., AHRING, B. K., LUBECK, P. S., et al., "Co-cultivation of Trichodermareesei RutC30 with three black Aspergillus strains facilitates efficient hydrolysis of pretreated wheat straw and shows promises for on-site enzyme production”, Bioresource Technology, v. 169, pp. 143-148, Oct. 2014.

[39] GARCIA-KIRCHNER, O., SEGURA-GRANADOS, M., RODRIGUEZ-PASCUAL, P., "Effect of media composition and growth conditions on production of beta-glucosidase by Aspergillusniger C-6", Applied Biochemistry and Biotechnology, v. 121, pp. 347-359, Mar. 2005.

[40] CUNHA, F. M., VASCONCELlOS, V. M., FLORENCIO, C., et al., "On-Site Production of Enzymatic Cocktails Using a Non-conventional Fermentation Method with Agro-Industrial Residues as Renewable Feedstocks", Waste and Biomass Valorization, v. 8, n. 2, pp. 517-526, Mar. 2017. 
[41] KNOB, A., FORTKAMP, D., PROLO, T., et al., "Agro-residues as Alternative for Xylanase Production by Filamentous Fungi”, Bioresources, v. 9, n. 3, pp. 5738-5773, Aug. 2014.

[42] ROBL, D., DELABONA, P. S., COSTA, P. S., et al.,"Xylanase production by endophyticAspergillusniger using pentose-rich hydrothermal liquor from sugarcane bagasse",Biocatalysis and Biotransformation, v. 33, n.3, pp. 175-187, May 2015.

[43] MILANEZI, N. G., GOMEZ MENDOZA, D. P., SIQUEIRA, F. G.,et al., "Isolation and Characterization of a Xylan-Degrading Enzyme from Aspergillusniger van Tieghem LPM 93 with Potential for Industrial Applications",BioenergyResearch, v. 5, n. 2, pp. 363-371, June 2012.

[44] BALA, A., SINGH, B.,"Cost-effective production of biotechnologically important hydrolytic enzymes by Sporotrichum thermophile",Bioprocess and Biosystems Engineering, v. 39, n. 1, pp. 181-191, Jan. 2016.

[45] ILUYEMI, F. B., HANAFI, M. M.,"Mycelial growth interactions and mannan-degrading enzyme activities from fungal mixed cultures grown on palm kernel cake",AfricanJournalofBiotechnology, v. 8, n. 10, pp. 2283-2288, May 2009.

\section{ORCID}

Thais Caliman Catelan

https://orcid.org/0000-0002-4166-9347

Laura Marina Pinotti

https://orcid.org/0000-0002-5012-6811 